\title{
Formal Linguistics and Language Education: Bridging the Gap
}

\author{
Andreas Trotzke and Tanja Kupisch
}

\begin{abstract}
In this chapter, we provide a brief introduction to recent work in linguistics that has its origin and motivation in formal linguistics and theoretical acquisition research, and on this basis indicates potential connections and contributions to language pedagogy, including students' and teachers' beliefs about what 'grammar' actually is.
\end{abstract}

Keywords Applied linguistics - Educational linguistics · Language education · Language pedagogy $\cdot$ Second language acquisition $\cdot$ Second language classroom

\section{Recent Attempts at Bridging the Gap}

Applying insights from formal linguistics to language teaching and teacher education is anything but new. However, recent years have seen a development of approaches within formal linguistics that aim to reach out and engage more actively with the field of language pedagogy (Whong et al. 2013; De Knop and Gilquin 2016; Marsden and Slabakova 2018; Gil and Rastelli 2018; Trotzke and Rankin 2020).

Given the conceptual background of established language-teaching methodologies such as Communicative Language Teaching or Critical Pedagogy, modern teacher education has shifted from the rigorous study of language structure to a focus on communicative and sociolinguistic underpinnings of teaching languages in a classroom. As a result, Applied Linguistics has expanded to address a range

\footnotetext{
A. Trotzke $(\bowtie)$

Department of Linguistics, University of Konstanz, Konstanz, Germany

Center for Theoretical Linguistics (CLT), Autonomous University of Barcelona, Barcelona, Spain e-mail: andreas.trotzke@uni-konstanz.de

T. Kupisch

Department of Linguistics, University of Konstanz, Konstanz, Germany

Department of Language and Culture, UiT The Arctic University of Norway, Troms $\emptyset$, Norway e-mail: tanja.kupisch@uni-konstanz.de
} 
of general societal issues involving language and communication, while one of the original concerns of linguistics, namely its application to language pedagogy, has moved away from the focus of attention. To refer to the more specific goal of applying linguistics to language pedagogy, researchers have established the term Educational Linguistics (see Hult 2008 for the historical development of this field, as well as the book series the present volume appears in). More specifically, Hult (2008: 17-18) states that

[t]he individual educational linguist, trained in any number of combinations of $[\ldots]$ relevant areas of study, might have her or his home in a variety of different departments, including anthropology, applied linguistics, area studies, education, English, foreign languages, linguistics, psychology, and sociology. Common to all educational linguists, though, is training in critical thinking of a transdisciplinary nature $[\ldots]$

Given this definition and understanding of an educational linguist, it follows that more sociology-oriented research areas such as language policy and language planning are a crucial part of Educational Linguistics too (see Spolsky 2005; Hult 2018). Our present volume on Formal Linguistics and Language Education does not deal with those issues, but instead focuses on work that has its origin and motivation in formal linguistics and theory-driven research on the acquisition of grammar, and on this basis tries to establish links to language pedagogy, including students' and teachers' beliefs about what 'grammar' actually is. By 'formal' and 'theoretical' approaches, we do not mean to refer to traditional language pedagogies that consider teaching and analyzing formal grammar as a goal in itself (like in branches of historical philology). Rather, we understand 'formal linguistics' as an umbrella term that encompasses all approaches - in theory or empirical acquisition research - using modern tools to analyze linguistic items beyond the word level (such as immediate constituent analysis, structuralist accounts of the language system, and specific syntactic approaches such as X-bar theory).

In the context of what we have said above about Applied Linguistics more generally and Educational Linguistics more specifically, we consider our volume a timely publication because insights from descriptive and theoretical linguistics, especially formal approaches to language and grammar, no longer have the natural channel to communicate issues and implications of language teacher training and Educational Linguistics that they once had. Furthermore, the work cited above, which has the explicit goal of linking formal linguistics to language pedagogy, often retains a strong theoretical allegiance, which makes it hard for outsiders to the theory to see the relevance to teaching. Also, in addition to being theoretically siloed, the contribution of work grounded in linguistic theory may face particular hurdles in addressing questions of educational relevance because often, as Widdowson (2003: 4) has put it, "the academic discipline of linguistics [...] is seen to be an abstruse field of enquiry at several removes from the reality of the language classroom" (see also Widdowson 2000). Recent studies have empirically shown that it is indeed the case that teachers refrain from consulting current linguistic research for reasons such as time constraints, insufficient access to online databases, insufficient knowledge of linguistic terminology (see Sato and Loewen 2019 and Marsden and Kasprowicz 
2017). Moreover, many sources that teachers actually do consult and that they think represent proper linguistic research might actually be of low quality, according to common standards and measures like the Social Sciences Citation Index, which help defining a field of inquiry such as linguistics and language acquisition research. Therefore, we, as linguists, should also take into account teachers' understanding of what exactly counts as research (see, e.g., Borg 2010 on this point). This situation with its potential confusions and ambiguities has already led researchers to conclude that "the findings of academic research are bound to be no less misleading and unreliable than teachers' experience and intuitions" (Medgyes 2017: 509), and that, consequently, there is nothing to gain from bridging the gap between linguistic research and language-pedagogy practitioners.

At the same time, and on a more positive note, linguists have sought to bridge this gap, without too much theoretical terminology and commitment to a specific framework. We would like to especially highlight Dick Hudson's work in this context. Hudson (2004, 2008, 2020) has repeatedly (and persistently) stressed that linguistics itself is fundamentally pedagogical, and it always has been. In particular, his work demonstrates that central linguistic concepts such as the first modern tree diagrams in syntax were developed and introduced in a pedagogical context: to improve the teaching of grammar in school. More generally, his historical observations indicate that our (read: the linguists') concepts of language have always been heavily influenced by education because language users are impacted by the specific language pedagogy they have experienced in school, and we as linguists are concerned with the actual behavior of those users. Accordingly, Hudson (2004: 105-106) points out that linguistics,

seen as a whole, has an important interface with education, and that research whose results cross this interface is just as important as that which feeds into, say, neuroscience or child development. [...] academic linguistics is weakened if we ignore the impact of education on language, so information must cross this interface in both directions.

Hudson thus argues for a two-way bridge between linguistics and education, encouraging both linguists and language-teaching practitioners to bridge the socalled research/practice divide. An important component of his work is that in this context he brings the formal properties of language to the fore. In line with this approach, the collection in our volume exemplifies that there is an increasing amount of (potential) research in formal linguistics more generally and in the linguistic approaches to language acquisition that might prove to be highly relevant and useful for teaching languages in the classroom.

Specifically, the present volume aims at bridging the gap between the 'social turn' in Educational Linguistics indicated above and formal approaches to natural language to eventually explore new teaching methodologies. Our collection of recent empirical work in this domain focuses especially on current accounts that envisage a subsequent integration of issues and insights from modern formal linguistics into language-teaching practice. We thus challenge recent comments and polemics on the research/practice divide, both from those who encourage stronger connections between academic research and pedagogical practice, and from 
those who see research as at best irrelevant to practice, or even as an unwelcome intervention in practice (see, e.g., Borg 2010; Marsden and Kasprowicz 2017; Medgyes 2017 for discussion).

The contributions to this volume cover a wide range of empirical linguistic domains and concern aspects of morphosyntax, including word order, inflectional morphology, article systems, pronouns, compounding patterns, as well as orthography and students' general beliefs about grammar. The first two articles in Part I of the volume (Conceptual Foundations) address the role of formal linguistic concepts for language teaching from a general perspective (Bayram and Rothman; Rankin and Whong), thereby introducing the broader picture and the conceptual starting point of many of the empirical papers in this volume. All other contributions report on empirical studies that cover settings relevant to the language classroom. In particular, while the first set of contributions (Part II: Native Language Settings) addresses the role of grammar instruction and language teaching in the native language, the second set (Part III: Second/Third Language Settings) focuses on empirical approaches to second and third language acquisition. In addition to discussing implications for language teaching, some of these studies explore experimentally how different teaching manipulations facilitate the learning of a second or third language.

We consider this volume as one further step towards shaping the emerging field of educational applications of theoretical and descriptive linguistics, and we hope it is of interest to a broad audience interested in state-of-the-art approaches to questions of linguistic theory and language acquisition that find applications in pedagogy.

\section{The Contributions}

\section{Part I: Conceptual Foundations.}

In their short conceptual contribution, Fatih Bayram and Jason Rothman sketch recent attempts at building bridges between formal linguistics and language education from the view of current research on bilingualism. Specifically, they outline the fundamental distinction between language acquisition and language learning, which has played a crucial role over the last decades, especially in the generative literature on second language acquisition. Bayram and Rothman then provide a short overview of recent research using explicit interventions and instructions in bilingual acquisition contexts. The authors conclude that this work underlines that language teaching can indeed benefit from linguistic research and pedagogical interventions inspired by formal linguistics.

Tom Rankin and Melinda Whong's chapter "Grammatical concepts for pedagogical grammar" is rooted in generative approaches to second language acquisition. The authors first develop the notion of "grammatical concept," suggesting that grammatical concepts can be derived from universal formal and semantic

distinctions. Rankin and Whong then propose ways of using these concepts to 
illuminate learnability issues in second language acquisition. To illustrate their approach, they outline some specific principles for the pedagogic use of grammatical concepts and apply them to the phenomenon of pronominal paradigms and usage - a phenomenon that combines different formal, semantic, and pragmatic notions because pronoun systems across languages vary along these three dimensions. More generally, Rankin and Whong highlight the importance of a linguistically-informed comparative approach to language pedagogy and suggest how learners can make use of specific analytical ways familiar to linguists, but not to most teachers working in language pedagogy.

\section{Part II: Native Language Settings.}

Daniel Gutzmann and Katharina Turgay also focus on grammatical concepts from a formal approach to natural language. In "Teaching word order variation with a constraint-based view on grammar," they argue that Optimality Theory can be used in the language classroom to teach word order patterns. Focusing on teaching German in German schools, they begin by illustrating the flexibility of German word order, explaining how it is determined by information-structural notions, such as topic and focus. At the same time, as the authors point out, German textbooks tend to represent German word order as if it was fairly rigid. Gutzmann and Turgay argue that students of German could benefit from being taught explicitly that word order is flexible and learn about the functions associated with the different word order patterns in order to structure their own texts coherently. They suggest that (a weighted version of) Optimality Theory can be useful for this purpose, illustrating two concrete scenarios that can be used to familiarize students with constraintbased thinking. The authors conclude by exploring how and where their approach can be implemented in the official (national and federal) standards of education in Germany.

Related to the contribution by Gutzmann and Turgay, Daniela Elsner also explores grammar teaching in the German education system. Her article "Grammar is irrelevant: The role of epistemological beliefs in students' learning success" deals with beliefs about grammar of students at German universities. Elsner draws on literature from education science that has shown a relation between epistemological beliefs and variables such as content knowledge, motivation, and self-concept. In accordance with this strand of research, Elsner postulates that epistemological beliefs function as a predictor for these other variables. The paper reports the results of a questionnaire study. While students' epistemological beliefs about grammar do not correlate with any other tested variables (i.e., content knowledge, motivation, and self-concept), poor performance in grammar tests does correlate with a lower motivation of the students, a worse self-concept, and the use of repetitive learning strategies. Based on these results, Elsner highlights that motivation is a key factor triggering learning processes, pointing out that there is a great need for reviewing academic curricula and implementing new teaching methods in order to enhance students' motivation.

Sandra Döring is concerned with students' beliefs about grammar too and investigates how these beliefs might be connected to common formal concepts of 
grammar. Her paper "Shaking students' beliefs about grammar: Some thoughts on the academic education of future language teachers" starts with the observation that although grammar courses constitute a basic component of the first academic phase of language teacher education, German teacher trainees do not feel confident about their knowledge of grammar. Döring highlights that students enter university with certain beliefs about grammar, which work like filters and thus heavily impact the students' learning success. Two large-scale questionnaire-based studies carried out at different German universities indicate that students see the relevance of grammar and grammar teaching, but nevertheless consider the topic too difficult and abstract. Based on these results, Döring first discusses formal areas of grammar knowledge that she considered essential for prospective teachers, and then goes on suggesting possibilities of how to teach these essentials whilst taking students' beliefs about grammar into account. Her general point is that grammar teaching for prospective teachers has to be different from grammar teaching for future linguistics researchers. Döring concludes by proposing new teaching and learning methods, highlighting how these can form a new generation of teachers in the context of universities and schools.

Björn Rothstein focuses on orthography - a topic of great importance for students at school. His article "Do linguistic landscapes influence the spelling competence of orthographic beginners? Two case studies" investigates to what extent wrong spellings in public spaces influence the spelling performances of beginning writers. In particular, Rothstein investigates the spelling of German N$\mathrm{N}$ compounds. Based on a corpus, he establishes the types and frequencies of misspellings. He then discusses a field experiment targeting the question whether wrong spellings in linguistic landscapes (here: 'writing in public spaces') has an impact on beginning writers. Although there were a lot of wrong spellings in the linguistic landscape investigated, the results of Rothstein's study suggest that these wrong spellings do not influence orthographic performance. Rothstein points to methodological issues in his study, arguing that linguistic landscapes might affect the spelling performance of beginning writers after all.

Part III: Second/Third Language Settings.

While the papers in Part II are dedicated to language teaching in the first (native) language classroom, those in Part III are concerned with teaching a foreign (i.e., second or third) language. In "The present tense in English, again" Amber Dudley and Roumyana Slabakova investigate the linguistic forms that can express aspectual meanings when talking about present events in English. In their study, they tested the effect of structural priming on the use of aspectual tense morphosyntax (present progressive and the present simple) in the English present tense by English native speakers, French upper-intermediate and French advanced L2 learners of English. Their findings demonstrate a high level of individual variation within the group of native English speakers. Moreover, structural priming in task instructions modulated both native and non-native speakers' choices of tense forms. In contrast to previous accounts, which interpreted optionality in aspectual choices as indicative of a representational deficit, Dudley and Slabakova argue that 
sensitivity to structural priming and the nature of the L2 input influence have a substantial impact on learner patterns. The implications are that teachers of English should take variation in the input into account, and researchers should be aware that structural priming in their instructions might affect study outcomes.

The paper by Neal Snape, "Post-instruction processing of generics in English by Japanese L2 learners," also deals with English as a second language, but from the perspective of native speakers of Japanese. The study focuses on article acquisition in generic contexts, testing in a self-paced reading task to what extent explicit instruction can affect real-time reading times. The general goal of this experiment is to find out whether explicit instruction can lead to faster reading times for the instruction group in the domain of definite kind sentences (e.g., The dodo is extinct), compared with a non-instruction group. The instructed group indeed displays faster reading times compared with the non-instruction group. Snape discusses some implications of his study for both theoretical concepts of second language acquisition and for teaching features of the English article system in the second language classroom. He concludes that even though explicit instruction might result in faster reading times and thus better performance, it is still unclear whether this improvement can be retained by learners over the long term.

Anders Agebjörn is also concerned with article acquisition in a second language. In "Explicit and implicit knowledge of article semantics in Belarusian learners of English: Implications for teaching," he investigates explicit and implicit knowledge of Russian and Belarusian learners of English, whose native languages lack articles. More specifically, Agebjörn asks whether the metalinguistic ability to explain what principles govern the use of definite and indefinite articles correlates with target-like use of articles in a communicative task that targets implicit knowledge. The study shows no correlation between explicit knowledge and the ability to use articles in the experimental setting. Agebjörn discusses his findings in the light of theoretical models in second language acquisition and suggests ways in which explicit instruction and knowledge can nevertheless be used to boost the development of implicit knowledge of English article semantics.

The volume concludes with Rosalinde Stadt, Aafke Hulk and Petra Sleeman's paper on "L2 influence in L3 acquisition: The role of the L3." The paper is concerned with third language (L3) acquisition, comparing different third languages (French and German), while keeping the first two languages (L1 Dutch, L2 German) (and other variables) constant. While previous studies found a significant effect of English on French word order patterns, the question of the present study was whether a similar result can be observed when the L3 is German and not French. To this end, Stadt et al. investigated intermediate learners of German (in secondary school) with regard to word order patterns. The results show that English plays a significantly smaller role in intermediate learners of L3 German compared to L3 French learners. Stadt et al.'s findings underline the role of typological relatedness and structural similarity between the Germanic languages Dutch, English, and German. More generally, their contribution highlights the relevance of taking into account the diversity of language profiles in the language classroom because all previously acquired languages may affect learner outcomes. 


\section{References}

Borg, S. (2010). Language teacher research engagement. Language Teaching, 43, 391-429.

De Knop, S., \& Gilquin, G. (Eds.). (2016). Applied construction grammar. Berlin: Mouton de Gruyter.

Gil, K. -H., \& Rastelli, S. (Eds.). (2018). Second language teaching and generative linguistics. Instructed Second Language Acquisition, 2 (Special Issue).

Hudson, R. (2004). Why education needs linguistics (and vice versa). Journal of Linguistics, 40, $105-130$.

Hudson, R. (2008). Linguistic theory. In B. Spolsky \& F. Hult (Eds.), The handbook of educational linguistics (pp. 53-65). Oxford: Blackwell.

Hudson, R. (2020). Towards a pedagogical linguistics. Pedagogical Linguistics, 1, 8-33.

Hult, F. (2008). The history and development of educational linguistics. In B. Spolsky \& F. Hult (Eds.), The handbook of educational linguistics (pp. 1-10). Oxford: Blackwell.

Hult, F. (2018). Language policy and planning and linguistic landscapes. In J. W. Tollefson \& M. Pérez-Milans (Eds.), Oxford handbook of language policy and planning (pp. 333-351). Oxford: Oxford University Press.

Marsden, E., \& Kasprowicz, R. (2017). Foreign language educators' exposure to research: Reported experiences, exposure via citations, and a proposal for action. The Modern Language Journal, 101, 613-642.

Marsden, H., \& Slabakova, R. (2018). Grammatical meaning and the second language classroom: Introduction. Language Teaching Research, 23, 147-157. https://doi.org/10.1177/ 1362168817752718.

Medgyes, P. (2017). The (ir)relevance of academic research for the language teacher. ELT Journal, $71,491-498$.

Sato, M., \& Loewen, S. (2019). Do teachers care about research? The research-pedagogy dialogue. ELT Journal, 73, 1-10.

Spolsky, B. (2005). Is language policy applied linguistics? In P. Bruthiaux, D. Atkinson, W. G. Eggington, W. Grabe, \& V. Ramanathan (Eds.), Directions in applied linguistics (pp. 26-36). Clevedon: Multilingual Matters.

Trotzke, A., \& Rankin, T. (2020). Editorial: Introduction to pedagogical linguistics. Pedagogical Linguistics, 1, 1-7.

Whong, M., Gil, K.-H., \& Marsden, H. (Eds.). (2013). Universal grammar and the second language classroom. Dordrecht: Springer.

Widdowson, H. G. (2000). On the limitations of linguistics applied. Applied Linguistics, 21, 3-25.

Widdowson, H. G. (2003). Defining issues in English language teaching. Oxford: Oxford University Press. 